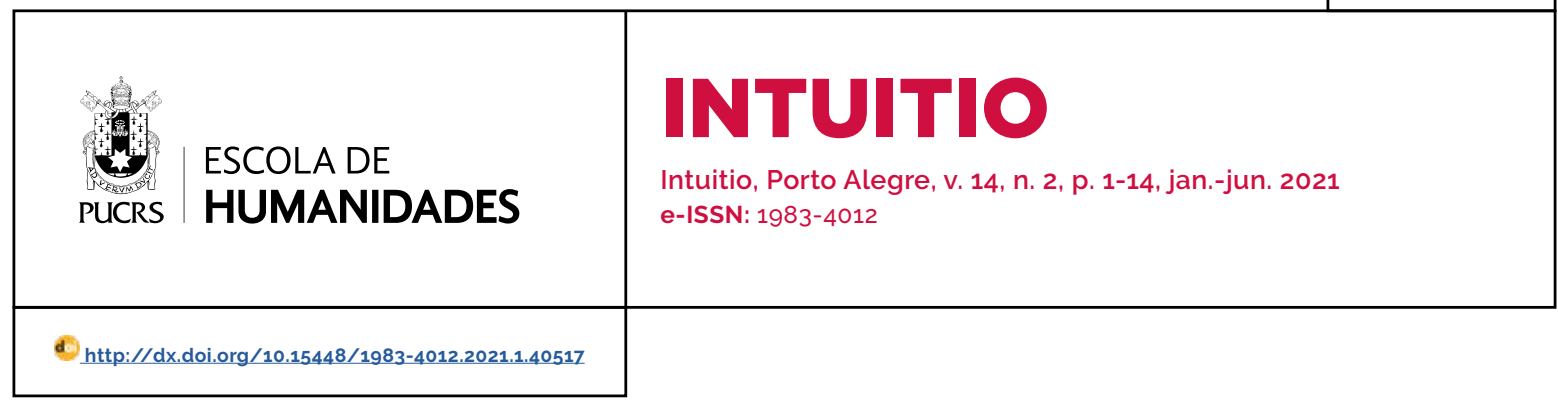

SEÇÃO ARTIGO

\title{
Restaurando a explicação do anulabilismo falibilista sobre o conhecimento a partir de crença falsa
}

Restoring the fallibilist defeasibility approach to knowledge from falsehood

\section{Eduardo Alves ${ }^{1}$}

orcid.org/0000-0002-9075-7554

eduardoalves.eas@gmail.com

Recebido em: 30/10/2020.

Aprovado em: 18/02/2021.

Publicado em: 02/09/2021.

\section{(c) (1)}

Artigo está licenciado sob forma de uma licença Creative Commons Atribuição 4.0 Internacional.
Resumo: O objetivo deste artigo é responder a duas objeções que podem ser feitas à explicação do anulabilismo falibilista referente à possibilidade de conhecimento inferencial originado em falsidade (KFF). A primeira objeção é que a ausência de restauradores indica a incompletude da explicação anulabilista falibilista de KFF, enquanto a segunda é que o experimento mental de KFF viola o Princípio Resistência à Verdade* $\left(\mathrm{RV}^{*}\right)$ - a principal tese do anulabilismo falibilista. Na primeira seção, explicarei no que consiste o debate acerca da possibilidade de conhecimento inferencial a partir de falsidade; na segunda seção, explicarei o anulabilismo falibilista, desenvolvida por de Almeida (2017); na última seção, desenvolverei os argumentos que podem ser feitos contra o anulabilismo falibilista e explicarei por que não funcionam.

Palavras-chave: Conhecimento a partir de crença falsa. Derrota epistêmica. Conhecimento inferencial.

Abstract: The aim of this essay is to respond to two objections which can be made against the fallibilist defeasibility approach to inferential knowledge from falsehood (KFF). The first objection is that the absence of restorers reveals the explanatory incompleteness of the theory with regard to KFF, while the second one is that the thought experiment aimed at explaining KFF violates the Truth-Resistance Principle* $\left(\mathrm{TR}^{*}\right)$ - the core thesis of Fallibilist Defeasibility Theory. In order to pursue the goals of this essay, I explain what the knowledge from falsehood debate is about; Secondly, I explain the fallibilist defeasibility approach developed by de Almeida (2017) to deal with KFF. Finally, I set the arguments up which can be brought against the fallibilist defeasibility approach and explain why they do not work.

Keywords: Knowledge from falsehood. Epistemic defeat. Inferential knowledge.

\section{Introdução}

"Conhecimento inferencial a partir de falsidade"2 (KFF) é o rótulo do problema sobre explicar se é possivel uma crença falsa produzir conhecimento inferencial. A questão nem é se crenças falsas produzem uma outra crença justificada candidata a conhecimento, nem se uma crença verdadeira sobredeterminada por uma crença falsa (seja causalmente, seja evidencialmente) pode vir a ser conhecimento. É, na verdade, um problema a respeito da possibilidade de o conhecimento ser originado em virtude de uma crença falsa em um episódio de raciocínio. Especificamente, é possivel que uma crença falsa seja essencial de modo causal e evidencial para a posse de conhecimento inferencial? 
Suponha que o conhecimento a partir de crença falsa seja um fenômeno genuíno. Se for um fenômeno genuíno, então é um dado a ser explicado pelas teorias do conhecimento, pois uma epistemologia satisfatória deve ser capaz de explicar os diversos tipos de conhecimento - isto é, iluminar a nossa compreensão sobre o conhecimento perceptual, testemunhal memorial, inferencial etc. Uma das propostas de explicação de "conhecimento a partir de crença falsa" é o anulabilismo falibilista, desenvolvido por Claudio de Almeida (2017). ${ }^{3}$ Esse autor oferece boas razões para preferir a sua versão de anulabilismo em relação às competidoras anulabilistas: a compatibilidade com o falibilismo da justificação e uma explicação sobre a geração de conhecimento inferencial em virtude de crença falsa. Nesse contexto, o objetivo deste artigo é responder a duas objeções que poderiam ser feitas à explicação anulabilista falibilista de "conhecimento a partir de crença falsa", proposta por de Almeida. A primeira delas é sugerir que a ausência de restauradores é um indicador da incompletude da explicação anulabilista de KFF, enquanto a segunda objeção pretende evidenciar que o experimento mental empregado para iluminar KFF viola o Princípio Resistência à Verdade* $\left(\mathrm{RV}^{*}\right)$ - a principal tese do anulabilismo falibilista. No que se segue, pretendo explicar no que consiste a possibilidade de conhecimento a partir de crença falsa e como o anulabilismo falibilista desenvolvido por Claudio de Almeida pretende explicá-la. Após esses esclarecimentos, examinarei as duas objeções e explicarei por que não funcionam.

\section{Conhecimento inferencial a partir de crença falsa}

Conhecimento inferencial é um tipo de conhecimento, segundo o qual um agente infere $p$ de uma crença (ou de uma suposição) em $q$ e, ao final do episódio de raciocínio ou do processo inferencial, há formação de crença verdadeira em $p$ e essa crença é um caso de conhecimento. ${ }^{4}$ Uma tese ortodoxa ${ }^{5}$ sobre a posse de conhecimento inferencial é a ideia de que ter conhecimento na premissa é condição necessária para obtenção de conhecimento inferencial de uma conclusão, caso seja derivada corretamente daquela premissa. ${ }^{6}$ Isto é, somente conhecimento produz conhecimento em episódios de raciocínio. O princípio que captura essa ideia pode ser expresso do seguinte modo:

\section{Contrafecho do Conhecimento (CFC) 7}

Necessariamente, se (i) S crê que $q$ apenas com base na inferência competente a partir de $p$, e (ii) $S$ sabe que q, então S sabe que p (LUZZI, 2019, p. 5). ${ }^{8}$

Uma razão para aceitar o princípio CFC é a capacidade de explicar a origem do status epistêmico da crença na conclusão. Se você desejasse transferir água de um balde para outro balde, o primeiro balde deveria conter água para a transferência ocorrer. Metaforicamente, algo similar ocorre com o conhecimento em episódios de raciocínio: a crença na premissa deve ser uma instância de conhecimento para a conclusão, derivada de modo apropriado com base nessa única premissa, ser um caso de conhecimento. Caso contrário, qual seria a origem do conhecimento da conclusão? A ideia central é que o status de conhecimento da premissa é transmitido para a conclusão. Esse principio sugere que inferências

\footnotetext{
3 Uma das primeiras propostas de explicação de "conhecimento a partir de crença falsa" é desenvolvida por Peter Klein (2008), por meio de uma análise das falsidades úteis e de uma reforma na condição anulabilista para a posse de conhecimento. Por uma questão de escopo, não abordarei essa proposta neste artigo

4 Durante este artigo, empregarei os termos "raciocínio" e "inferência" como sinônimos.

5 É uma tese ortodoxa, pois há indício do endosso a ela durante boa parte da história da filosofia. Aristóteles (2016, 72a25-30) provavelmente endossaria essa tese. Outros autores, como Descartes, Russell e Williamson, também aceitariam essa ideia. Para referências sobre esses autores a essa tese ortodoxa, veja Borges (2017, 2020).

6 A "derivação correta", ou "derivação apropriada", significa que a inferência ou o raciocinio do agente está em conformidade com as regras de avaliação de inferências dedutivas ou indutivas.

7 Essa expressão é uma tradução de "Knowledge Counter-Closure".

8 Um outro principio relacionado ao CFC é o Principio de Fecho do Conhecimento, cuja ideia central é que conhecimento é condição suficiente para a aquisição de conhecimento inferencial. O princípio CFC não é um princípio contrário ao do Fecho do Conhecimento: o "contra" ("counter") é apenas um indicador de que o foco está na necessidade em vez da suficiência. Para mais informações sobre os principios de Fecho, veja de Almeida (2020)
} 
são fontes transmissoras de conhecimento: para a crença em $p$, derivada da crença em $q$, ser uma instância de conhecimento, a crença em $q$ deve ser um caso de conhecimento por meio da percepção, da memória, do testemunho ou da intuição racional. O raciocínio, ou a inferência, não podem gerar conhecimento; apenas transmitir o conhecimento originado de outra fonte. ${ }^{9}$

Como o conhecimento é factivo, isto é, necessariamente, se um agente sabe que $p$, então $p$ é verdadeira, se o princípio CFC é verdadeiro, é necessário que crença-alvo de conhecimento seja derivada de uma premissa verdadeira. Em função disso, a premissa da qual a crença-alvo é derivada deve ser, no mínimo, verdadeira para avaliarmos se tal crença pode ser uma instância de conhecimento. Uma consequência do principio CFC e da necessidade de premissa verdadeira é a impossibilidade de adquirir conhecimento inferencial a partir de crença falsa. ${ }^{10}$ Não será possivel obter conhecimento desse modo se, e somente se, a crença falsa for essencial para a formação da crença-alvo. ${ }^{11} \mathrm{~A}$ crença em q é essencial para que a crença em $p$ seja um caso de conhecimento se, e somente se, a base causal e o suporte evidencial de $p$ provêm de $q .{ }^{12}$ Então, se a crença falsa, $q$, é essencial de modo causal e evidencial para a formação da crença-alvo, $p$, então a crença em p não pode ser uma instância de conhecimento.

Há boas razões para crer que é verdadeira a tese de que crenças falsas não podem produzir conhecimento inferencial. Uma delas é a suposição de que a de que a inferência apropriada a partir de premissas que são casos de conhecimento é a norma do raciocínio teórico, conforme argumenta Borges (2020). Embora um agente possa inferir apropriadamente $p$ de uma crença falsa, q, p não será uma instância de conhecimen- to por não estar em conformidade com a norma. Outra razão é uma das lições aprendidas com as tentativas de solução ao problema de Gettier. Suponha que um agente creia justificadamente com base na experiência perceptual que há uma ovelha no campo. Com base nessa crença, ele infere que há um animal no campo e forma uma crença verdadeira e justificada nesse conteúdo. Contudo, a crença da qual a conclusão é derivada é falsa: o agente está olhando para um holograma de ovelha, não uma ovelha genuína. Então, a crença de que há uma ovelha no campo é falsa. Contudo, a crença-alvo é verdadeira, pois há um cachorro escondido atrás de um arbusto e fora do campo visual do agente. ${ }^{13}$ Nesse caso, o agente não está em posse de conhecimento e uma das explicações para a ausência de conhecimento é o fato de a crença-alvo ser derivada essencialmente de uma crença falsa. Para a crença-alvo ser um caso de conhecimento, a crença falsa não pode ser essencial para a formação de tal crença. Essa é uma tese tão atrativa que foi, grosso modo, uma das primeiras propostas de solução ao problema de Gettier. Michael Clark (1963) argumenta que uma das condições necessárias para a posse de conhecimento é não haver fundamentos falsos para a crença-alvo. O endosso de Gilbert Harman (1973, p. 120) a essa tese também é explícito ao alegar que o "raciocínio o qual essencialmente envolve conclusões falsas, intermediárias ou finais, não pode produzir conhecimento". Em função disso, a seguinte generalização está justificada: nenhuma crença verdadeira derivada essencialmente de uma crença falsa pode ser uma instância de conhecimento.

Embora essa generalização seja atrativa, não é óbvio que seja verdadeira, pois há casos presentes na literatura de suposto conhecimento

\footnotetext{
9 Para mais informações sobre o caráter transmissor da inferência, veja Luzzi (2019) e Audi (2011).

10 Essas teses impossibilitam também a obtenção de conhecimento inferencial a partir de crença gettierizada e de crença injustificada, por exemplo. Para mais informações, veja Luzzi (2014, 2019), Olivier (2019), Murphy (2017).

11 Embora possa haver casos nos quais uma crença verdadeira e uma crença falsa, independentes entre si, sejam os fatores causais e evidenciais de uma outra crença verdadeira que é uma instância de conhecimento, perceba que esse tipo de caso não é um contraexemplo ao princípio CFC. Por hipótese, o conhecimento da crença-alvo seria mantido caso a crença falsa fosse perdida, pois a crença verdadeira seria suficientemente capaz de prover a base causal e evidencial a crença-alvo.

12 Embora Klein (2008, p. 43) ofereça uma definição da relação de essencialidade entre uma premissa e uma conclusão, ele não se compromete com a ideia de que crenças falsas possam ser causal e evidencialmente essenciais para a posse de conhecimento inferencial. Para Klein, crenças falsas podem ser apenas causalmente essenciais para a obtenção de conhecimento inferencial.

13 Esse exemplo é inspirado no caso Ovelha no Campo, proposto por Chisholm (1989).
} 
inferencial obtido essencialmente por meio de crença falsa. Se tais casos são genuínos, então é falsa a tese generalizada de que nenhuma crença verdadeira derivada essencialmente de uma crença falsa pode ser um caso de conhecimento. Se houver conhecimento a partir de crença falsa, então nem é necessário que a premissa seja um caso de conhecimento, nem que a premissa seja verdadeira, para a uma crença verdadeira derivada essencialmente dessa premissa ser uma instância de conhecimento. Para ilustrar isso, considere os casos Handout e Papai Noel:

[Handout]: Ao contar com cuidado o número de pessoas presentes na minha plateia, eu raciocínio: 'Há 53 pessoas na minha plateia; portanto, as minhas 100 cópias do handout são suficientes'. Minha premissa é falsa, há 52 pessoas na plateia - eu contei duas vezes uma pessoa que trocou de lugar durante a contagem. Ainda assim, eu sei a minha conclusão (WARFIELD, 2005, p. 407-408).

[Papai Noel]: Mamãe e Papai dizem à pequena Virgínia que o Papai Noel colocará alguns presentes sob a árvore na véspera do Natal. Crendo no que seus pais dizem, Virgínia infere que haverá presentes sob a árvore na manhã de Natal. Ela sabe disso (KLEIN, 2008, p. 37).

Ambos os casos são estruturalmente idênticos. A crença-alvo é verdadeira e inferida competentemente de uma crença falsa justificada. Em cada caso, é atrativa a ideia de que o agente esteja em posse de conhecimento e seja devido à crença falsa, pois essas falsidades seriam essenciais de modo causal e evidencial para a crença-alvo ser um caso de conhecimento. Apesar disso, há aspectos próprios em cada caso. No caso do Papai Noel, há uma asserção falsa de testemunhas geralmente sinceras, contudo, que estão mentindo na situação específica do Natal. Em Handout, há um erro de percepção na formação da crença na premissa. Esses erros, no entanto, não impedem que a crença falsa goze de excelente status epistêmico positivo. Em relação à crença na conclusão, ela é verdadeira e inferida de modo competente a partir de crenças justificadas pela percepção e pelo testemunho. Diferentemente do caso do animal no campo apresentado anteriormente, essa crença verdadeira, inferida de uma crença falsa justificada, seria um caso de conhecimento. Essa atribuição de conhecimento ao agente dos casos, inclusive, é compativel com as nossas intuições de senso comum sobre o conhecimento, conforme indicam os experimentos de John Turri (2019). ${ }^{14}$

Uma tese bastante plausivel a respeito da natureza do conhecimento é a ideia segundo a qual se um agente sabe que $p$, então a crença de que $p$ não é acidentalmente verdadeira (PRITCHARD, 2016). Os casos Gettier fortalecem essa alegação: o agente gettierizado não está em posse de conhecimento porque a crença-alvo é verdadeira por sorte. Em relação aos casos de KFF, Warfield (2005, p. 408) sugere que tais cenários são instâncias de conhecimento a partir de falsidade, pois a cadeia de justificação da crença falsa até a crença-alvo é estável. ${ }^{15} \mathrm{~A}$ formação de uma crença verdadeira de modo estável significa que o alcance da verdade não é devido a um elemento do acaso, a um elemento fortuito. Ou seja, a crença-alvo não é verdadeira por sorte. Se uma crença verdadeira, derivada de modo apropriado de uma crença falsa, não é acidentalmente verdadeira, é razoável atribuirmos conhecimento ao agente que realiza essa inferência. Outra sugestão é argumentar que, nos casos de KFF, não há contraevidências para a crença verdadeira derivada da crença falsa, conforme propõe de Almeida (2017). Devido a essas considerações teóricas, há justificação prima facie para crermos que os casos Handout e Papai Noel são casos genuinos de conhecimento a partir de falsidade.

Caso haja conhecimento a partir de crença falsa e, portanto, seja possivel adquirir conhecimento inferencial com base em crença falsa e conhecimento seja condição necessária para a posse de conhecimento inferencial, então não

14 Uma metodologia relativamente recente é uso de investigação empírica para a avaliação de teses filosóficas, conhecida como filosofia experimental ( $X$-Phi, em inglês). O objetivo dessa metodologia é empregar as ferramentas das ciências empíricas - como a ciência cognitiva, por exemplo - para avaliar a interpretação do senso comum de teses filosóficas e se essas interpretações são compativeis com a teorização filosófica. Para mais informações, veja, respectivamente, Knobe e Nichols (2017) e Williamson (2018).

15 Essa ideia de estabilidade da crença verdadeira derivada da crença falsa é melhor desenvolvida por Luzzi (2019). 
é possivel endossar de modo consistente essas duas teses. Defensores da possibilidade de KFF argumentam contra o principio CFC, sob o ônus de oferecer uma explicação para distinguir entre crenças falsas produtoras de conhecimento e crenças falsas produtoras de ignorância, ou seja, diferenciar entre casos de KFF e casos Gettier inferenciais com falsidade.

Esse pode ser um movimento heterodoxo demais. Uma opção mais conservadora disponivel aos críticos de KFF é rejeitar que crenças falsas sejam evidencialmente essenciais para a posse de conhecimento inferencial e oferecer uma explicação alternativa para a origem do status epistêmico da crença-alvo, $p$, sem negar que a crença em $p$ seja uma instância de conhecimento. Autores simpáticos a esse movimento argumentariam que um proxy epistêmico é o fator que confere status epistêmico positivo à crença-alvo. ${ }^{16} \mathrm{Um}$ proxy epistêmico é uma crença verdadeira (qualificada com outras propriedades) ou uma proposição verdadeira (qualificada com outras propriedades). Sob uma perspectiva geral, o proxy epistêmico é um substituto da função que a crença falsa exerceria na explicação do conhecimento inferencial. No caso do Papai Noele Handout, os candidatos a proxy epistêmico podem ser <alguém colocará presentes sob a árvore de Natal> e <há aproximadamente 53 pessoas na plateia $>$. Peter Klein (2008), um defensor da tese de que o proxy epistêmico é uma proposição verdadeira, argumenta que a epistemização da crença-alvo é devida a essas proposições verdadeiras, enquanto a causação ocorre em virtude da crença falsa. Para Klein, é importante salientar que as proposições proxies conferem status epistêmico à crença-alvo; crenças falsas, por outro lado, desempenham apenas o papel causal no episódio de raciocínio. Autores como Montminy (2014), Ball e Bloome-Tillmann (2014) e Borges (2017, 2020), diferentemente de Klein, creem que o proxy epistêmico é uma crença verdadeira capaz de desempenhar a função causal e evidencial da crença-alvo, sem a necessidade de recorrer à crença falsa para explicar a posse de conhecimento inferencial. Em função disso, a crença falsa seria um elemento dispensável no episódio de raciocínio: ela poderia ser removida do sistema doxástico do agente sem prejudicar o histórico causal e evidencial da crença-alvo. Argumentar desse modo, definindo o proxy epistêmico como uma proposição verdadeira ou como uma crença verdadeira, significa sugerir que a descrição mais adequada do fenômeno nos casos Papai Noel e Handout é conhecimento apesar de falsidade, ${ }^{17}$ em vez de conhecimento a partir de falsidade. ${ }^{18}$

Infelizmente, está além do escopo deste artigo analisar cada uma das posições e argumentar a favor de uma delas. Em função dos objetivos deste ensaio, assumirei que há conhecimento a partir de crença falsa e, na próxima seção, explicarei como o anulabilismo falibilista propõe-se a explicar esse fenômeno. ${ }^{19}$

\section{0 anulabilismo falibilista}

Suponha um agente que saiba que está em Porto Alegre. Além disso, suponha que, em um tempo posterior, ele venha a saber que não está em Salvador. É plausível supor que o conhecimento anterior de que ele está em Porto Alegre não será perdido quando o conhecimento novo a respeito de não estar em Salvador for adquirido. Uma lição epistemológica importante pode ser aprendida desse exemplo: o conhecimento deve ser compativel com mais conhecimento. Isto é, o conhecimento "velho" deve ser consistente com o conhecimento "novo". Essa é uma ideia sugerida por Hintikka (1962, p. 22): conhecimento não é perdido ao ganharmos mais conhecimento. Como o conhecimento é factivo, se conhecimento deve ser compativel com mais conhecimento, então conhecimento deve ser compativel com mais proposições verdadeiras que o agente possa vir a crer. Como os anulabilistas conservam a noção

\footnotetext{
O rótulo "proxy epistêmico" é criado por Luzzi (2014).

Essa expressão é uma tradução de "knowledge despite falsehood".

Para criticas à abordagem de Klein, veja de Almeida (2017). Para críticas às propostas de "conhecimento apesar de falsidade", veja Buford e Cloos (2018), Fitelson (2017) e Luzzi (2018).

19 Para uma revisão dos principais argumentos a favor e contra a possibilidade de conhecimento a partir de falsidade, veja Alves (2021).
} 
de justificação epistêmica presente na análise da tradicional do conhecimento, eles argumentam que, em um caso de conhecimento, a justificação da crença-alvo deve ser resistente à verdade, isto é, os justificadores da crença-alvo devem ser consistentes com mais proposições verdadeiras que o agente possa vir a saber (KLEIN, 1981). A crença, por hipótese, justificada do agente de que que ele está Porto Alegre não será mantida de modo irracional caso ele venha a crer que não está em Salvador. Entretanto, caso esse agente esteja em uma situação na qual a justificação para a crença-alvo não é resistente à verdade, então tal justificação será epistemicamente defeituosa por não acomodar consistentemente mais proposições verdadeiras que o agente possa vir a saber. Caso a justificação da crença-alvo seja defeituosa, a crença-alvo não será um caso de conhecimento. Por exemplo, a justificação para crer que o agente está em Porto Alegre não será resistente à verdade caso, por hipótese, ele venha a saber que está sob o efeito de substâncias psicoativas fortíssimas, que o impedem de saber a sua localização atual.

Essas proposições verdadeiras indicadores da "não-resistência" à verdade da justificação são derrotadores (defeaters), isto é, proposições verdadeiras que impediriam o agente de manter racionalmente a crença-alvo. Se pensarmos no caso Gettier apresentado na seção anterior, a proposição verdadeira <você está vendo um holograma de ovelha> destrói a justificação perceptual para crer que o animal é uma ovelha. Caso o agente viesse a saber que está olhando para um holograma de ovelha, apenas a experiência perceptual não seria suficiente para manter racionalmente a crença de que o animal é uma ovelha.

Além da noção de derrotador, os conceitos de cadeia de justificação e cadeia de derrota são essenciais para a compreensão da proposta anulabilista. Uma cadeia de justificação é o conjunto de justificadores que conferem status epistêmico positivo à e até a proposição-alvo. Isto é, seja jo símbolo para "justificador" e $p$ para "proposição-alvo", j justifica $j_{1}, j_{1}$ justifica $j_{n}, j_{n}$ justifica $p$. Uma cadeia de derrota, por sua vez, é o conjunto de proposições verdadeiras, $d$, que tornam plausiveis outras proposições verdadeiras, $d_{1^{\prime}}$ até $d_{n^{\prime}}$, capazes de danificar qualquer um dos elos da cadeia de justificação. Na explicação acima, o derrotador < você está vendo um holograma de ovelha > afeta diretamente a justificação da crença de que o agente está vendo uma ovelha. Nesse caso, não é necessário derivar nenhuma outra proposição verdadeira para efetivar a derrota. Em função disso, é uma derrota direta da justificação. Caso fosse necessário derivar outras proposições verdadeiras para efetivar a derrota, a derrota seria indireta. Nesse cenário, apenas $d$ não é suficiente para efetivar a derrota; $d_{n}$ também seria o elemento essencial para a efetivação da derrota. Ou seja, $d$ seria o derrotador inicial, enquanto $d_{n}$ seria o derrotador efetivo. Conforme sugere Klein (1981, p. 141-146), o derrotador efetivo é responsável por neutralizar a relação evidencial entre $j_{n}$ e $p$, enquanto o derrotador inicial é o fator que torna plausivel os elos seguintes da cadeia de derrota.

A proposta do anulabilismo é inserir uma cláusula antiderrota da justificação como condição necessária de uma análise do conhecimento. Um agente sabe que $p$ somente se não há derrotadores da justificação para $p$. Entretanto, uma análise que incorpore essa condição será muito forte por oferecer o veredicto incorreto a alguns casos de conhecimento. Uma análise anulabilista do conhecimento, caso seja satisfatória, deve distinguir entre o que Klein (1981) caracteriza como derrota genuina e derrota enganadora. Considere o exemplo proposto por Lehrer e Paxson (1969), motivador dessa distinção:

[Sra. Grabit]: Eu vejo um sujeito que me parece ser Tom Grabit roubando um livro na biblioteca. Minha observação do sujeito e do comportamento dele (sob boa iluminação, em uma distância curta, recordando-me de como Tom se parece) não deixa espaço para dúvida: ( $p)$ o ladrão deve ser Tom Grabit. Contudo, sem que eu o saiba, (d) a Sra. Grabit, mãe de Tom, testemunha que, enquanto Tom estava viajando, o irmão gêmeo dele estava na biblioteca no dia em questão. No entanto, também sem que eu o saiba, (r) a Sra. Grabit sofre de Alzheimer e está fazendo uma alegação falsa sobre um gêmeo que sequer existe. Foi de fato Tom quem roubou o livro (DE ALMEIDA; FETT, 2016, p. 156). 
Se esse é um caso de conhecimento, a teoria da anulabilidade "não-qualificada" oferece uma resposta contrária às nossas intuições. A proposição verdadeira, $d$, <a senhora Grabit testemunha que o irmão gêmeo de Tom estava na biblioteca e Tom está viajando> derrota a justificação para crer que Tom é o ladrão. Se o agente viesse a crer que $d$, ele seria irracional ao manter a crença-alvo. No entanto, essa não parece ser uma explicação correta da situação, uma vez que o testemunho de uma fonte inconfiável não deveria afetar nosso conhecimento. Por isso, é necessário retificar a noção de derrota da justificação.

Em casos típicos de conhecimento, pode haver derrota enganadora da justificação, isto é, uma derrota ilusória da justificação, porque o efeito de aparente derrota da justificação dependerá de uma proposição falsa atuando como derrotador efetivo (KLEIN, 1981; DE ALMEIDA; FETT, 2016). No caso da Sra. Grabit, a proposição verdadeira, $d$, <a Sra. Grabit testemunha que o irmão gêmeo de Tom estava na biblioteca e Tom está viajando> torna plausivel a proposição falsa, $d_{f^{\prime}}<$ Tom possui um irmão gêmeo que roubou a biblioteca $>$ e $d_{f}$ é a responsável por neutralizar a justificação perceptual do agente. Se $d$ e $d_{f}$ fossem inseridas no sistema doxástico do agente, a crença-alvo de que Tom roubou a biblioteca não poderia ser racionalmente mantida apenas com as experiências perceptuais. No entanto, esse ataque à justificação é ilusório e pode ser neutralizado pelo que Klein (1981) define como um restaurador: uma proposição verdadeira, incapaz de conferir status epistêmico positivo à crença-alvo, capaz de neutralizar o efeito ilusório causado pela proposição falsa que atua como derrotador efetivo. ${ }^{20}$ O restaurador, $r$, <A Sra. Grabit sofre de Alzheimer> é capaz de cancelar o efeito do derrotador efetivo falso, pois, caso o agente viesse a acreditar no testemunho da Sra. Grabit a respeito do suposto irmão gêmeo de Tom e que ela sofre de Alzheimer, ele plausivelmente não tomaria o testemunho dela como contraevidência para a crença de que
Tom é o ladrão. Note, também, que r não é capaz de justificar a crença-alvo. Isto é, $r$ não confere status epistêmico à proposição-alvo; ele apenas evidencia que o derrotador inicial a respeito do testemunho da Sra. Grabit não é capaz de destruir genuinamente a justificação perceptual, pois sua capacidade de ser um derrotador é parasitária de uma proposição falsa. Sob uma perspectiva geral, uma derrota é enganadora se, e somente se, todo derrotador inicial torna plausivel um derrotador efetivo falso e a conjunção desses derrotadores com os justificadores para $p$ não justificam $p$.

Por outro lado, em um caso típico de ignorância, a derrota será genuína, isto é, o último elo da cadeia de derrota será uma proposição verdadeira, capaz de destruir a justificação para p. Caso uma justificação seja derrotada genuinamente, essa justificação não será resistente à verdade. Em alguns casos, sequer será necessário derivar uma cadeia de derrota para efetivar a derrota genuina: o derrotador inicial pode ser, ao mesmo tempo, o derrotador efetivo. É importante enfatizar que, diferentemente da derrota enganadora, não há proposição verdadeira capaz de restaurar o status justificatório da justificação original. Uma justificação derrotada genuinamente não é passivel de restauração epistêmica. Sob uma perspectiva geral, uma derrota é genuína se, e somente se, todo derrotador inicial torna plausivel um derrotador efetivo verdadeiro e a conjunção desses derrotadores com os justificadores para $p$ não justificam $p$.

Em função da distinção entre derrota genuína e derrota enganadora, a sugestão de Klein é que, para todo caso de conhecimento, é condição necessária que não haja derrotadores genuínos para a justificação para p. Alternativamente, para todo caso de conhecimento, todo derrotador da justificação para $p$ é um derrotador enganador. Embora essa condição complete a análise anulabilista do conhecimento e acomode nossas reações intuitivas para casos de conhecimento e de ignorância, ela não é satisfeita nos casos de KFF. No caso Handout, a negação da crença falsa,

20 A cláusula de que o restaurador não é capaz de conferir status epistêmico à proposição-alvo é necessária para evitar que qualquer proposição verdadeira desempenhe o papel de restaurador. Em todos os casos Gettier, por exemplo, há várias proposições verdadeiras capazes de epistemizar a crença-alvo, contudo, isso não significa que tais proposições restaurem a justificação original. 
<não há 53 pessoas na plateia>, derrota genuinamente a justificação da crença de que as 100 cópias são suficientes. Se o agente viesse a crer que não há 53 pessoas na plateia, a justificação proveniente da crença falsa não seria suficiente para manter racionalmente a crença de que as 100 cópias do handout são suficientes. A consequência disso é que todo caso de conhecimento a partir de crença falsa é julgado erroneamente pelo anulabilismo de Klein como uma instância de ignorância. Ou seja, o anulabilismo de Klein é incompativel com a possibilidade de conhecimento inferencial a partir de falsidade. ${ }^{21}$

Embora o anulabilismo de Klein seja atrativo, a incapacidade de acomodar o conhecimento a partir de crença falsa é uma razão que depõe contra a atratividade da teoria. Se você for um entusiasta do falibilismo acerca da justificação, então essa proposta será ainda menos atrativa. 0 falibilismo sobre justificação epistêmica é a tese de que um agente pode ter crença justificada e falsa. Ou seja, conforme uma concepção falibilista de justificação, os justificadores de $p$ não garantem a verdade de $p$. A respeito do anulabilismo, perceba que a condição de justificação resistente à verdade é bastante liberal a respeito de quais proposições verdadeiras podem neutralizar o status epistêmico de uma justificação. A princípio, qualquer proposição verdadeira que apoie um derrotador efetivo verdadeiro poderia derrotar a justificação para $p$. Se um agente crê verazmente que $p$ e com base no testemunho de uma pessoa sob o efeito de substâncias psicoativas, a proposição verdadeira indicando o fato de que essa pessoa é inconfiável é um derrotador da justificação testemunhal. Da mesma forma, se um sujeito crê falsamente que $p$, mas com excelente justificação, a negação de $p$ será um derrotador da justificação para $p$. Se a justificação pode ser derrotada genuinamente, então essa justificação não será resistente à verdade.

Se o falibilismo acerca da justificação é atrativo, a explicação sobre a derrota da justificação de crenças falsas pode soar imprópria. Se o falibilismo da justificação é verdadeiro, então uma crença falsa pode estar apoiada por excelentes razões e tais razões seriam suficientes para o limiar de uma crença estar justificada ser satisfeito. Não haveria diferença de grau entre a justificação para uma proposição verdadeira e para uma proposição falsa; ambas podem estar justificadas em nivel de conhecimento. ${ }^{22}$ Entretanto, o anulabilismo de Klein não acomoda essa ideia, uma vez que, para toda justificação para uma falsidade, há um derrotador genuíno: a proposição contraditória verdadeira. Conforme explicado, a derrota genuína é um indício de justificação "não-resistente" à verdade. Em função disso, conforme argumenta de Almeida (2017), a justificação para uma falsidade nunca será resistente à verdade e, por conseguinte, nunca terá o status epistêmico equivalente ao status de uma justificação de uma proposição verdadeira.

Por hipótese, se a justificação para uma proposição falsa e a justificação para uma proposição verdadeira podem ter o mesmo grau, por que nenhuma justificação para uma falsidade é resistente à verdade? Parece que, em um cenário mais genérico, o único defeito dessa justificação é apoiar uma proposição falsa. Como é impossivel haver crença falsa justificada e "não-derrotada" genuinamente, a condição da verdade é trivialmente satisfeita pela justificação resistente à verdade. Isto é, necessariamente, se a condição da ausência de derrotadores é satisfeita, então a condição da verdade é satisfeita - porque apenas a justificação para proposições verdadeiras pode ser resistente à verdade. A consequência disso é que o anula-

\footnotetext{
21 Essa incompatibilidade é considerada por Klein como uma objeção séria ao anulabilismo no artigo "Useful False Beliefs" (2008). Nesse artigo, Peter Klein propõe uma revisão na teoria da anulabilidade para acomodar a intuição de que há conhecimento nesses casos. O objetivo de Klein é acomodar a intuição de que a crença falsa é próxima da verdade, pois a crença falsa justifica proposicionalmente uma proposição verdadeira, e essa proposição é capaz de conferir justificação proposicional à crença-alvo. Embora a justificação doxástica fornecida pela crença falsa seja alvo de derrota genuina, a justificação proposicional oriunda da proposição verdadeira não é derrotada genuinamente. Por não ser derrotada genuinamente, podemos considerar os casos como instâncias de conhecimento. Para mais informações, veja Klein (2008); para criticas, veja de Almeida (2017). Infelizmente, está além do escopo deste ensaio analisar detalhadamente a proposta de Klein. 22 "Justificação em nivel de conhecimento" é uma expressão utilizada por Claudio de Almeida, e pretende capturar a ideia de knowledge-grade justification. Para ele, "justificação em nivel de conhecimento é sinônimo de justificação que é boa o suficiente para o conhecimento em qualquer maneira concebivel" (DE ALMEIDA, 2017, p. 300, nota 22)
} 
bilismo de Klein é infalibilista. Entretanto, é uma forma sagaz de infalibilismo, na qual a verdade da crença é garantida pela ausência de derrotadores genuínos, diferentemente das formas mais usuais de infalibilismo, em que a evidência ou o método de formação garante a verdade da crença. ${ }^{23}$

Se a argumentação de Claudio de Almeida é persuasiva, não é possivel aceitar consistentemente o anulabilismo de Klein e o falibilismo da justificação. Contudo, de Almeida sugere uma mudança bastante conservadora na teoria de Klein, capaz de acomodar o falibilismo da justificação e preservar as principais virtudes teóricas do anulabilismo de Klein. A proposta de Claudio de Almeida é reformular a ideia de justificação resistente à verdade e restringir o escopo de proposições verdadeiras capazes de derrotar genuinamente a justificação. Se o falibilismo acerca da justificação é verdadeiro, a simples negação de uma falsidade não pode ser um derrotador da justificação para uma proposição falsa, porque isso seria equivalente a alegar que o defeito dessa justificação é justificar uma falsidade. Em um contexto de debate, por exemplo, em que teses contraditórias estão em disputa, não é razoável que a mera asserção da negação de uma falsidade, p , seja suficiente para derrotar a justificação para p. A justificação seria derrotada, de Almeida provavelmente sugeriria, se o objetor oferecesse razões "não-equivalentes" à $\sim p$ e tais razões fossem suficientes para destruir o suporte epistêmico para a falsidade. Desse modo, a reformulação da noção de resistência à verdade é a seguinte:

\section{Principio de Resistência à Verdade*}

$\left(R V^{*}\right)$ Se S possui justificação em nivel de conhecimento para crer que $p$ em $t$, então apenas [v] não-logicamente equivalentes à p podem derrotar a justificação em $t$, mas não há $[v]$ que faça isso (DE ALMEIDA, 2017, p. 301). ${ }^{24}$

A ideia defendida por de Almeida é a de que $\sim p$ e seus equivalentes lógicos não podem derrotar a justificação para uma falsidade, p. Se a crítica à justificação de uma proposição falsa, $p$, depende apenas do contraditório verdadeiro, $\sim p$, ou seus equivalentes lógicos, então a justificação para essa falsidade é resistente à verdade. Isso possibilita que a justificação para proposições falsas possa estar em nivel de conhecimento e gozar do mesmo grau de status epistêmico de uma justificação para uma proposição verdadeira. O anulabilismo falibilista de Claudio de Almeida, ao incorporar o princípio RV*, é uma proposta compatível com o falibilismo acerca da justificação e, ao ter a condição de ausência de derrotadores genuínos satisfeita, não acarreta a verdade da crença. ${ }^{25}$

Outra razão para aceitar o anulabilismo falibilista proposto por de Almeida é por oferecer uma explicação da possibilidade de conhecimento a partir de crença falsa. Claudio de Almeida (2017, p. 307) sugere que a intuição subjacente aos casos de KFF é que as crenças falsas "são tão boas quanto [crenças verdadeiras] em raciocínios". Se a justificação para uma falsidade pode ser resistente à verdade, acredito que algumas crenças falsas também podem ser tão boas quanto o conhecimento em episódios de raciocínio - conhecimento é um excelente fator, tanto causal, quanto evidencial, no processo inferencial, afinal. Crenças falsas que instanciam essas propriedades são falsidades benignas por serem capazes de conferir status epistêmico positivo equivalente ao oferecido por proposição verdadeiras ou por conhecimento. A consequência disso é que, caso uma crença verdadeira seja justificada por uma falsidade benigna, essa justificação será objeto de derrota enganadora, isto é, essa justificação não será objeto de derrota genuína. Por outro lado, algumas falsidades são malignas por serem incapazes de produzir conhecimento, porque, ao justificarem uma crença, tal justificação será objeto de derrota genuina. Com a distinção entre falsidades benignas e malignas, é possivel diferenciar entre casos de

\footnotetext{
${ }_{23}$ Claudio de Almeida (2017) caracterizou essas formas como "infalibilismo pela porta dos fundos" (back-door infallibilism) e "infalibilismo pela porta da frente" (front-door infallibism), respectivamente.

24 Neste contexto, os símbolos " $v$ " e " $t$ " significam, respectivamente, "proposição verdadeira" e algum período do tempo.

25 Para críticas ao principio RV*, formulado por Claudio de Almeida, veja Fett (2019). Por uma questão de escopo, não há espaço neste artigo para avaliar a crítica de Fett.
} 
conhecimento inferencial a partir de falsidade e casos Gettier inferenciais com falsidade. ${ }^{26}$

Se essa explicação é atrativa, então não haverá derrotadores genuínos da justificação nos casos de KFF. No caso Handout, por exemplo, de Almeida (2017, p. 309) sugere que a proposição verdadeira <não há 53 pessoas na plateia> derrota a justificação para a crença de que $p$ e ela é o derrotador inicial. Essa proposição torna plausivel o derrotador efetivo, $d_{n^{\prime}}<$ as 100 cópias podem não ser suficientes>. No entanto, isso não é compativel nem com o conhecimento de fundo do agente sobre o ambiente no qual se encontra, nem com o conhecimento sobre o número de cópias que carrega. Não é razoável que esse derrotador efetivo seja um derrotador efetivo genuíno, isto é, não é plausivel que $d_{n}$ seja uma proposição verdadeira. Isso significa que $d_{n}$ é um derrotador efetivo falso e isso evidencia que a justificação originada da falsidade benigna é derrotada de modo enganador, não de modo genuíno. Se $d_{n}$ fosse uma proposição verdadeira, teríamos que pensar na possibilidade absurda de que as 100 cópias não fossem suficientes para 53 pessoas em uma plateia. Devido a isso, a justificação para a crença-alvo, proveniente da crença falsa benigna, não é genuinamente derrotável. Qualquer derrotador para a justificação dessa cadeia é enganador por tornar plausivel um derrotador efetivo falso. Essa teorização pode ser generalizada: para todo caso de KFF, a justificação originada da falsidade benigna é apenas alvo de derrotada genuína. Alternativamente, não há derrotadores genuínos para a justificação proveniente da falsidade benigna. Essa é a explicação do anulabilismo falibilista para a possibilidade de conhecimento inferencial a partir de falsidade.

\section{Princípio $\mathrm{RV}^{*}$ e restauração epistêmica}

Embora a explicação de KFF de Claudio de Almeida seja atrativa para clarificar o fenômeno, alguém poderia objetar que ela viola uma tese central do anulabilismo falibilista: o princípio $\mathrm{RV}^{*}$.
Não apenas isso, mas essa violação também poderia ocorrer sob ângulos distintos ao selecionarmos derrotadores e restauradores. Se a explicação de conhecimento a partir de crença falsa violar uma das condições necessárias da cláusula antiderrota, isto é, violar o princípio $\mathrm{RV}^{*}$, então a explicação não será plenamente satisfatória. Outra objeção também pode ser feita à explicação anulabilista-falibilista de KFF: de Almeida não oferece restauradores da justificação da crença-alvo. Por ser um elemento central ao quadro anulabilista, a ausência desse elemento tornaria a explicação incompleta. Responderei as duas objeções e argumentarei contra cada uma delas.

Ao explicar um caso de conhecimento com as ferramentas anulabilistas, indagamos se a justificação do agente é alvo de derrota enganadora, isto é, se não há derrotadores genuínos da justificação para $p$. Ao encontrar um candidato a derrotador enganador, é possivel identificar um candidato a restaurador da justificação capaz de neutralizar o efeito ilusório causado pela proposição falsa. Contudo, o experimento mental para explicar o conhecimento em Handout sequer menciona um possivel restaurador da justificação proveniente da crença falsa benigna. Ao analisar o caso sob o ângulo da derrota enganadora, um restaurador deveria ser oferecido para a explicação estar completa e ser equivalente a um caso de conhecimento, assim como é no caso da Sra. Grabit.

No entanto, isso não é tão grave quanto possa parecer, pois há alternativas de restauradores da justificação para serem oferecidos. A proposição verdadeira <há 52 pessoas na plateia>, individualmente, poderia restaurar a justificação proveniente da crença falsa benigna, porque o efeito do derrotador efetivo falso, <as 100 cópias podem não ser suficientes> seria cancelado. Contudo, essa proposição não é um restaurador epistêmico, pois ela não restabelece o status epistêmico originado da crença falsa benigna. Essa proposição criaria uma nova justificação, isto é, é um elemento capaz de, individualmente,

26 Essas definições apenas delimitam quando uma falsidade é capaz de produzir justificação em nivel de conhecimento, uma vez que não é o caso que toda crença falsa justificada em nível de conhecimento é capaz de produzir conhecimento. Para uma falsidade produzir conhecimento, as outras condições da análise anulabilista do conhecimento devem ser satisfeitas. 
conferir status epistêmico à crença-alvo e tal status não dependeria em nenhum sentido da crença falsa benigna. ${ }^{27}$

A ausência de restauradores, no entanto, não ameaça a explicação anulabilista-falibilista de KFF. Oferecer restauradores é um luxo ao qual não é necessário o anulabilista se submeter. O que é imprescindivel é o defensor do anulabilismo falibilista oferecer boas razões para crer que todos os derrotadores iniciais serão enganadores, porque a cadeia de derrota a qual iniciam terminará em um derrotador efetivo falso. Em função disso, a justificação proveniente de crença falsa benigna não será objeto de derrota genuína, uma vez que nenhum derrotador inicial tornará plausivel um derrotador efetivo verdadeiro.

A segunda objeção é a que a explicação anulabilista-falibilista de KFF viola o principio $\mathrm{RV}^{\star}$. O comprometimento com o princípio $\mathrm{RV}^{*}$ e violá-lo ao explicar KFF significa sustentar uma diade inconsistente. Ao comprometer-se com o princípio $\mathrm{RV}^{\star}$, o contraditório verdadeiro da falsidade ou seus equivalentes lógicos não podem ser oferecidos como derrotadores de uma cadeia de justificação cujo um dos elos é a proposição falsa. Entretanto, é exatamente esse movimento que de Almeida realiza ao explicar KFF com a sua proposta. Isto é, de Almeida sugere $\sim$, <não há 53 pessoas na plateia>, como um derrotador inicial enganador da justificação. Uma vez que o status epistêmico da crença-alvo de que as 100 cópias do handout são suficientes depende da crença falsa benigna, $q$. <há 53 pessoas na plateia>, a sugestão de Claudio de Almeida não é consistente com o princípio RV*, pois isso seria equivalente a criticar a justificação apenas por apoiar uma proposição falsa. Como a crença-alvo <as 100 cópias são suficientes> é justificada pela crença falsa benigna <há 53 pessoas na plateia>, Claudio de Almeida, portanto, não poderia oferecer $\sim q$ como um derrotador inicial da justificação da crença-alvo.

Há, pelo menos, duas maneiras de defender que a explicação anulabilista-falibilista de KFF é consistente com o principio $\mathrm{RV}^{*}$ : a) argumentar que o princípio $\mathrm{RV}^{*}$ é uma tese sobre quais proposições verdadeiras derrotam genuinamente a justificação; e b) conceder que o experimento mental proposto viola o principio $\mathrm{RV}^{*}$ e oferecer um experimento alternativo, com proposições verdadeiras capazes de evitar a crítica de inconsistência com o princípio $\mathrm{RV}^{*}$.

A primeira estratégia de defesa é argumentar que, embora a objeção de inconsistência possa ter alguma atratividade, ela repousa em uma interpretação equivocada, tanto do princípio RV* quanto da noção de derrota enganadora. Quando a justificação para $p$ é alvo de derrota enganadora, esse ataque, por ser enganador, depende de uma proposição falsa atuando como derrotador efetivo. Isso, entretanto, não é um indicador de que a justificação não é resistente à verdade. Não é à toa que Klein (2017) começou a descrever a derrota enganadora como uma pseudoderrota, uma vez que o efeito de derrotador depende exclusivamente de uma proposição falsa, em vez de uma proposição verdadeira - como é o caso na derrota genuína. O princípio $\mathrm{RV}^{*}$, por sua vez, é uma tese sobre quais proposições verdadeiras derrotam genuinamente a justificação para $p$, isto é, quais derrotadores efetivos são indicadores da "não-resistência" à verdade da justificação. Conforme expliquei na seção anterior, como apenas o contraditório verdadeiro, q, ou seus equivalentes lógicos não são suficientes para causar algum dano à justificação da proposição falsa, $q$, o princípio $\mathrm{RV}^{*}$ não será violado ao empregar $\sim q$ como um derrotador inicial na cadeia de derrota enganadora para explicar o conhecimento a partir de crença falsa. Ou seja, não haverá violação do princípio $\mathrm{RV}^{*}$ ao utilizar $\sim q$ como um derrotador inicial enganador contra a justificação originada da falsidade benigna, $q$. O princípio é bastante permissivo em relação a esse tipo de caso. Haveria violação caso a negação da crença falsa benigna fosse, ao mesmo tempo, o derrotador inicial e efetivo - porque isso significaria que a justificação da

27 Assim como o próprio Claudio de Almeida já lembrou a comunidade filosófica (cf. DE ALMEIDA; FETT, 2016), algumas proposições verdadeiras podem restaurar a justificação, enquanto outras podem criar uma nova justificação. Esse é um detalhe sutil e, se negligenciado, pode resultar em uma tese absurda de que os sujeitos gettierizados possuem conhecimento. Essa consequência é apontada por John Turri (2012), devido a sua interpretação equivocada da teoria da anulabilidade. 
falsidade benigna é defeituosa simplesmente por apoiar uma falsidade. Sob uma perspectiva geral, é permissivel ao anulabilista-falibilista empregar consistentemente a negação da crença falsa benigna como um derrotador inicial enganador, caso ela torne plausivel um derrotador efetivo falso. 0 princípio $\mathrm{RV}^{*}$ impede que apenas a negação de falsidade ou seus equivalentes lógicos sejam derrotadores iniciais e efetivos da justificação para essa proposição falsa. Ou seja, evita que a negação da falsidade benigna seja um derrotador genuíno da cadeia de justificação, cujo um dos elos é a crença falsa benigna.

A segunda estratégia de defesa consiste em aceitar que a objeção de violação do principio RV* é atrativa em algum sentido e, em função disso, em oferecer um experimento mental alternativo para explicar KFF. A atratividade da crítica repousa no fato de que a derrota enganadora afeta, mesmo que em grau mínimo, a justificação para $p$, pois uma derrota enganadora é iniciada por proposições verdadeiras, afinal. Formar crenças nessas proposições verdadeiras poderia diminuir o grau de justificação da crença-alvo. Devido a isso, ao teorizar sobre um caso de conhecimento a partir de crença falsa, pode parecer incômodo empregar a negação da falsidade benigna na cadeia de derrota contra a justificação da falsidade benigna. Esse desconforto é similar a infeliz situação de presenciarmos o melhor jogador do nosso time de futebol cometer um gol contra. Um gol contra, embora seja um movimento permitido no futebol é, no mínimo, desagradável. Similarmente, embora empregar a negação da falsidade benigna contra a justificação da falsidade benigna seja uma estratégia explanatória permissivel, isso é, no mínimo, teoricamente desagradável.

O teórico do anulabilismo falibilista, todavia, é capaz de contornar esse desconforto ao oferecer um novo experimento mental que satisfaça o principio $\mathrm{RV}^{*}$ e que seja teoricamente agradável. É bastante plausivel supor que a nossa capacidade de contar pessoas em uma plateia seja limitada. Por conter muitas pessoas, podemos facilmente cometer erros de contagem. Podemos pular uma fila de pessoas ou não enxergar uma pessoa que não esteja tão visivel em meio à plateia. Isso também é evidenciado pelo fato de que o agente viu o rosto de um dos membros da plateia e o contou outra vez quando estava em outro assento. Plausivelmente, o agente o contou pela segunda vez após ter contado inúmeras pessoas. Suponha que isso o tornasse inconfiável contando pessoas em um auditório lotado. Contudo, somos faliveis. Cometer pequenos erros esporadicamente não é um indício de que nossas faculdades cognitivas são inconfiáveis. Por conseguinte, o erro local do agente não é algo que o torne inconfiável. Esse raciocínio pode ser traduzido no seguinte experimento mental:

A proposição verdadeira <o agente errou a contagem> é um derrotador inicial da justificação da crença-alvo. Dado que o auditório está lotado e que o agente havia contado inúmeras pessoas ao contar uma determinada pessoa duas vezes, essa proposição torna plausivel o derrotador efetivo, $r$, <o agente é inconfiável contando pessoas na plateia>. Contudo, não é razoável que, dada a nossa falibilidade, um erro fortuito solape as inúmeras vezes em que o agente foi confiável contando pessoas em uma plateia. Não é plausivel que $r$ seja um derrotador efetivo verdadeiro, isto é, um derrotador genuino. ré um derrotador efetivo falso e isso significa que é possivel encontrar um restaurador, $\sim r$, como, por exemplo, <o agente é confiável contando pessoas em uma plateia>. Esse restaurador, $\sim$, seria capaz de restabelecer o status epistêmico da justificação oriunda da crença falsa benigna.

Em princípio, esse experimento mental é consistente com o principio $\mathrm{RV}^{*}$, pois não há inconsistência entre os derrotadores sugeridos e a falsidade benigna. Entretanto, a inconsistência aparece sob outro ângulo na relação entre a restauração epistêmica e o derrotador efetivo falso. Perceba que a restauração epistêmica pode ser compreendida como um derrotador do derrotador ou um papa-derrotador, ${ }^{28}$ pois o

28 Inclusive, Klein (1981, p. 154) e de Almeida e Fett (2016, p. 157, 166) caracterizam o restaurador como um elemento capaz de cancelar o efeito do derrotador enganador. 
seu papel é neutralizar o efeito causado pelo derrotador efetivo falso. Em função da relação entre o restaurador e a derrota enganadora ser uma relação entre uma proposição verdadeira neutralizando o efeito de uma proposição falsa, é plausivel que a escolha de restauradores epistêmicos deva satisfazer o principio $\mathrm{RV}^{*}$. Isto é, é razoável que o principio $\mathrm{RV}^{*}$ também seja uma tese sobre quais restauradores podem neutralizar o efeito do derrotador efetivo falso. Se o princípio $\mathrm{RV}^{*}$ também é uma tese aplicável à seleção de restauradores epistêmicos, então não é possivel que r seja um restaurador da justificação, pois $\sim r$ é a contraditória verdadeira do derrotador efetivo falso, $r$. Sugerir que $\sim r$ poderia neutralizar o efeito do derrotador efetivo falso, $r$, seria equivalente a alegar que a negação de uma falsidade, q, pode cancelar a justificação de uma falsidade, q. Em função das semelhanças com a justificação de uma falsidade e a derrota epistêmica, a proposição verdadeira, r, não pode ser um restaurador capaz de cancelar o efeito ilusório de derrota enganadora por esta ser dependente de um derrotador efetivo falso, $r$. Entretanto, o experimento mental acima sugere exatamente isto: empregar r para cancelar o efeito ilusório de $r$. Isso também é um modo de violar o princípio $\mathrm{RV}^{*}$.

Entretanto, a violação do princípio $\mathrm{RV}^{*}$ no âmbito da restauração epistêmica não é algo que deva preocupar o anulabilista-falibilista. Conforme argumentei, a oferta de restauradores epistêmicos é um empreendimento que o anulabilista não precisa, necessariamente, se comprometer. No entanto, caso for realizá-lo, a escolha tanto de restauradores, quanto de derrotadores efetivos genuínos, deve satisfazer o principio RV*. A escolha de derrotadores iniciais é mais permissiva nesse aspecto.

\section{Considerações finais}

Espero ter oferecido ao leitor uma boa explicação a respeito do debate sobre a possibilidade de conhecimento inferencial a partir de crença falsa e do tratamento anulabilista-falibilista, desenvolvido por Claudio de Almeida, a esse problema. Especificamente, espero ter oferecido ao leitor boas razões para crer que a) a ausência de restauradores não é um indício de incompletude na explicação anulabilista-falibilista de KFF; que b) a explicação do anulabilismo falibilista de KFF é consistente com o princípio $\mathrm{RV}^{*} \mathrm{e}$, por fim; que c) a seleção de restauradores epistêmicos deve satisfazer o principio RV*. Sob uma perspectiva geral, o anulabilismo falibilista de Claudio de Almeida permanece sendo uma opção bastante plausivel para iluminar a possibilidade de conhecimento inferencial a partir de crença falsa.

\section{Referências}

ALVES, Eduardo. Raciocínio com Falsidades: Um Ensaio sobre Conhecimento Inferencial. 2021. 145 p. Dissertação (Mestrado em Filosofia) - Programa de Pós-Graduação em Filosofia, PUCRS, Porto Alegre, 2021. Disponivel em: http://tedez.pucrs.br/tedez/handle/ tede/9559. Acesso em: 1 maio 2021.

ARISTÓTELES. Analíticos posteriores. In: ARISTÓTELES. Órganon: Categorias, Da Interpretação, Analíticos anteriores, Analíticos posteriores, Tópicos, Refutações sofísticas. São Paulo: Edipro, 2016. p. 265-365.

AUDI, Robert. Epistemology: A Contemporary Introduction to the Theory of Knowledge. 3. ed. New York: Taylor \& Francis, 2011.

BALL, Brian; BLOME-TILLMANN, Michael. Counter Closure and Knowledge despite Falsehood. Philosophical Quarterly, [S. I.] v. 64, n. 257, p. 552-568, 2014.

BORGES, Rodrigo. Inferential Knowledge and The Gettier Conjecture. In: BORGES, Rodrigo; DE ALMEIDA, Claudio de; KLEIN, Peter. (ed.). Explaining Knowledge: New Essays On The Gettier Problem. Oxford: Oxford University Press, 2017. p. 273-291.

BORGES, Rodrigo. Knowledge from Knowledge. American Philosophical Quarterly, [S. I.], v. 57, n. 3. p. 283-298, 2020. https://dx.doi.org/10.2307/48574439.

BUFORD, Christopher; CLOOS, Christopher Michael. A Dilemma for the Knowledge despite Falsehood Strategy. Episteme, [S. I.], v. 15, n. 2, p. 166-182, 2018. https:// dx.doi.org/10.1017/.epi.2016.53.

CHISHOLM, Roderick. Theory of Knowledge. New Jersey: Prentice Hall, 1989.

CLARK, Michael. Knowledge and Ground: A Comment on Mr. Gettier's Paper. Analysis, [S. I.], v. 24, n. 2, p. 4648,1963

DE ALMEIDA, Claudio; FETT, J. R. Defeasibility and Gettierization: a reminder. Australasian Journal of Philosophy, [S. I.], v. 94, n. 1, p. 152-169, 2016.

DE ALMEIDA, Claudio. Knowledge, Benign Falsehoods, and the Gettier Problem. In: BORGES, Rodrigo; DE ALMEIDA, Claudio; KLEIN, Peter. (ed.). Explaining Knowledge: New Essays On The Gettier Problem. Oxford: Oxford University Press, 2017. p. 292-311. 
DE ALMEIDA, Claudio. Epistemic Closure and Epistemological Optimism. Philosophia, [S. I.], v. 49, p. 113-131, 2021. https://doi.org/10.1007/s11406-020-00206-5.

FETT, João Rizzio. O que é o conhecimento?: Uma introdução à epistemologia contemporânea. Porto Alegre: EDIPUCRS, 2019.

FITELSON, Branden. Closure, Counter-Closure, and Inferential Knowledge. In: BORGES, Rodrigo; DE ALMEIDA, Claudio; KLEIN, Peter. (ed.). Explaining Knowledge: New Essays On The Gettier Problem. Oxford: Oxford University Press, 2017. p. 312-324.

HARMAN, Gilbert. Thought. Princeton, New Jersey: Princeton University Press, 1973.

HINTINKKA, Jaako. Knowledge and Belief: An Introduction to the Logic of the Two Notions. Ithaca: Cornell University Press, 1962.

KLEIN, Peter. Certainty: A Refutation of Scepticism. Minneapolis: University of Minnesota Press, 1981.

KLEIN, Peter. Useful false beliefs. In: SMITH, Quentin. (ed.). Epistemology: New Essays. New York: Oxford University Press 2008. p. 30-64

KLEIN, Peter. The Nature of Knowledge. In: BORGES, Rodrigo.; DE ALMEIDA, Claudio; KLEIN, Peter. (ed.). Explaining Knowledge: New Essays On The Gettier Problem. Oxford: Oxford University Press, 2017. p. 35-56.

KNOBE, Joshua; NICHOLS, Shaun. Experimental Philosophy. In: The Stanford Encyclopedia of Philosophy. ZALTA, Edward N. (ed.). Winter, 2017. Disponivel em: https:// plato.stanford.edu/archives/win2017/entries/experimental-philosophy/. Acesso em: 1 de março de 2021.

LEHRER, Keith; PAXSON, Thomas. Knowledge: Undefeated justified true belief. Journal of Philosophy, [S. I.], v. 66, n. 8, p. 225-237, 1969.

LUZZI, Federico. What Does Knowledge-yielding Deduction Require Of Its Premises? Episteme, [S. I.], v. 11, n. 3, p. 261-275, 2014.

LUZZI, Federico. Knowledge from Non-Knowledge: Inference, Testimony and Memory. Cambridge: Cambridge University Press. 2019. http://dx.doi. org/10.1017/9781108649278

MONTMINY, Martin. Knowledge Despite Falsehood. Canadian Journal of Philosophy, [S. I.], v. 44, n. 3-4, p. 463-475, 2014.

MURPHY, Peter. Justified Belief from Unjustified Belief. Pacific Philosophical Quarterly, [S. I.], v. 98, n. 4, p. 602-617, 2017.

OLIVIER, K. Agent Reliabilism and Inferential Knowledge from Gettiered Belief. Episteme, [S. I.], p. 1-16, 2020. http://dx.doi.org/10.1017/.epi.2020.15

PRITCHARD, Duncan. Knowledge. 2. ed. New York: Palgrave Macmillan, 2016.

TURRI, John. In Gettier's wake. In: HETHERINGTON, Stephen. (ed.). Epistemology: The Key Thinkers. New York: Continuum, 2012. p. 214-229.
TURRI, John. Knowledge from Falsehood: An Experimental Study. Thought: A Journal of Philosophy, [S. I.], v. 8, n. 3, p. 167-178, 2019.

WARFIELD, Ted. Knowledge From Falsehood. Philosophical Perspectives, [S. I.], v. 19, n. 1, p. 405-416, 2005.

WILLIAMSON, Timothy. Doing Philosophy: From Common Curiosity to Logical Reasoning. Oxford: Oxford University Press, 2018

\section{Agradecimentos}

Gostaria de agradecer ao Claudio de Almeida pelas discussões dos vários tópicos aqui expostos. Agradeço também ao André Neiva, Gregory Gaboardi, Felipe Medeiros, Gustavo Oliva, João Fett, Miguel Egler, Sandy Goldberg e Vinicius Posselt pelas conversas sobre os principais tópicos abordados neste texto durante o 11th Principia International Symposium, em Florianópolis. A pesquisa que resultou neste artigo foi apoiada financeiramente pelo PPG em Filosofia da PUCRS e pelo CNPq.

\section{Eduardo Alves}

Mestre em Filosofia pela Pontificia Universidade Católica do Rio Grande do Sul (PUCRS), em Porto Alegre, RS, Brasil.

\section{Endereço para correspondência}

Pontificia Universidade Católica do Rio Grande do Sul Av. Ipiranga, 6.681, Prédio 4, sala 2

Partenon, 97010-082

Porto Alegre, RS, Brasil

Os textos deste artigo foram revisados pela Poá Comunicação e submetidos para validação do autor antes da publicação. 